\title{
Boletín
}

Criminológico

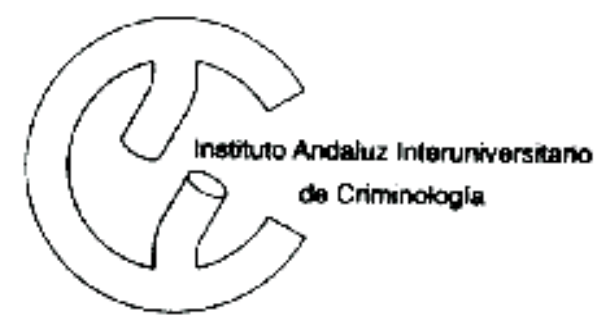

Directora: Elisa García España

Coordinadora: Susana García Ruiz

Publicado por la Sección de Málaga del IAIC

Edificio Institutos de Investigación, Universidad

de Málaga. Campus de Teatinos, 29071 MALAGA

Tel:(95) 2132325 - Fax:(95) 2132242

Depósitolegal: MA 857/1996ISSN:1137-2427

www.uma.es/estudios/propias/criminologia

Los delitos de robo y hurto callejeros suelen provocar en los ciudadanos una percepción de inseguridad que en ocasiones llega a modificar los hábitos de los vecinos de una zona con el objetivo de evitar el riesgo de ser víctima de uno de ellos. Sin embargo, al hurto en comercios cometido por clientes o trabajadores de esa empresa no se le suele prestar atención y se asume como una pérdida desconocida dentro de los presupuestos.

En este nuevo número del boletín se resalta la importancia cuantitativa que llega a tener esa pérdida desconocida y su correlación con los gastos en seguridad de las distintas formas comerciales según comunidades autónomas. La nueva inversión en seguridad se presenta como una de las medidas preventivas a considerar si se quieren reducir las pérdidas por este motivo.

\section{EL HURTO EN EL COMERCIO MINORISTA ESPAÑNOL}

\section{INTRODUCCIÓN}

En el ámbito empresarial el hurto lo padece, en su mayor parte, el comercio detallista. Directamente concernidas se encuentran también las empresas de fabricación y suministro de sistemas de seguridad en su labor de búsqueda de las soluciones posibles.

Distintos estudios que han sido realizados en España sobre el fenómeno del hurto en la distribución comercial revelan que la cuantía media de pérdidas por esta causa representa alrededor del $1 \%$ de la cifra de ventas totales. Genéricamente, el concepto de pérdida desconocida es el término que se utiliza en la gestión de la empresa para cuantificar las desviaciones económicas que se derivan del hurto.

\section{LA PÉRDIDA DESCONO- CIDA}

La prevención de las pérdidas va adquiriendo una mayor importancia en la planificación es- tratégica de las empresas, que están reconociendo los riesgos que conlleva la pérdida desconocida por las elevadas cifras de negocio que se malogran.

La pérdida desconocida es la diferencia que existe entre las existencias teóricas y las reales, una vez que se efectúa la correspondiente auditoría contable. Es la parte de las mermas que no ha podido ser identificada y justificada por causas conocidas, por lo que, a los efectos de la contabilidad de la empresa, ocupan un epígrafe específico (García Reche, 1996).

Haciendo hincapié en la idea del desconocimiento de las causas de la pérdida de los stocks, es necesario matizar que los hurtos, robos y fraudes detectados no se computan como pérdida desconocida en la organización comercial. Sin embargo, nos ceñimos a este concepto puesto que recoge de una manera más fiable las cifras del
Jesús ManuelLópez Bonilla Luis Miguel López Bonilla

hurto efectivo.

La pérdida desconocida se origina por tres causas, que son: el hurto externo, el hurto interno y los errores administrativos. El hurto externo se refiere a las sustracciones de los clientes. Aunque se ha demostrado que tan sólo un porcentaje pequeño de consumidores comete este tipo de infracciones, cualquier cliente de un establecimiento comercial puede ser potencialmente causante de un delito de hurto en un momento determinado.

En cambio, el hurto interno está representado por la acción delictiva de los empleados en el $80 \%$ de los casos, y de los proveedores y subcontratistas en el $20 \%$ restante. La relevancia de este motivo de pérdidas se sustenta en la mayor facilidad para la comisión del delito gracias al alto grado de conocimiento del lugar y las formas de trabajo, y al elevado nivel de confianza que significa la 
pertenencia o proximidad a la empresa. Por todo ello, la detección del hurto interno resulta muy complicada, ya que conlleva la provocación de una situación laboral de malestar.

Por último, los errores administrativos aluden al empleo de procedimientos inadecuados por parte de los empleados, aunque también pueden ocultar a veces alguna de las modalidades del hurto interno .

\section{EL HURTO EN EL CO- MERCIO MINORISTA EN ESPAÑA}

Según el estudio sobre la pérdida desconocida en la distribución comercial española que ha realizado la Asociación Española de Codificación Comercial (AECOC), se estima que el número de hurtos externos detectado durante el año 1995 representó un $0,64 \%$ de las ventas totales de las empresas encuestadas, oscilando el valor medio de la mercancía sustraida entre las 1000 y las 5000 pesetas.

Las cifras más elevadas de incidencias se producen en los hipermercados, seguidas de los grandes almacenes y, a mayor distancia, los supermercados y tiendas especializadas.

Puede observarse la existencia de esa misma relación desde la perspectiva del valor económico de la mercancía sustraída. En este sentido, el hurto de productos cuyo precio es inferior a cinco mil pesetas se produce principalmente en supermercados, mientras que el hurto valorado en cuantías superiores aparece con más frecuencia en los hipermercados y en los grandes almacenes.

Respecto a la incidencia del hurto interno en España, conforme al estudio de AECOC, se estima que el valor medio de la mercancía sustraida por el personal de la empresa representa un $28 \%$ de las ventas totales de las empresas encuestadas, lo que prueba que en el hurto interno la pérdida económica es ostensiblemente superior.

En el hurto externo domina ampliamente la sustracción de bebidas alcohólicas (que afecta a un $73 \%$ de los establecimientos comerciales), colonias y perfumes caros y material de bazar de pequeño tamaño (69\% de comercios afectados).

En el hurto interno también ocupa la primera posición por importancia ese tipo de mercancías, pero seguido muy de cerca de los descuentos a familiares y amigos, y del dinero en efectivo, afectando igualmente a un $69 \%$ de los comercios.

En cuanto a la localización de las incidencias, se observa que en el hurto externo hay un mayor riesgo en el fondo de la tienda, mostradores y rincones. A su vez, en el hurto interno destacan las sustracciones en las cajas de salida del establecimiento y en el área de recepción de la mercancía.

El horario comercial en el que se comete el hurto externo con mayor frecuencia es el comprendido entre las 13 y las 17 horas, seguido por el de las 17 a 19 horas. Igualmente destacan los viernes y sábados (ambos representan un $66 \%$ de las infracciones) como los días de la semana más afectados.

Otro factor relevante es la

TABLA1

Pérdida desconocida y gastos de seguridad por formas comerciales

\begin{tabular}{|c|c|c|c|}
\hline $\begin{array}{c}\text { FORMATOS } \\
\text { COMERCIALES }\end{array}$ & $\mathrm{N}^{\mathrm{a}}$ EMPRESAS & $\begin{array}{c}\text { PÉRDID A DESC } \\
\text { Media (\%) }\end{array}$ & $\begin{array}{c}\text { SEGURID AD } \\
\text { Media }(\%)\end{array}$ \\
\hline Gran Almacén & 46 & 2,79 & 0,97 \\
\hline Hipermercados & 67 & 1,16 & 0,71 \\
\hline Supermercados & 52 & 0,78 & 0,26 \\
\hline Super+Perfumería & 97 & 0,65 & 0,50 \\
\hline Super+Otros & 20 & 1,09 & 1,09 \\
\hline Almacén Popular & 25 & 1,32 & 1,00 \\
\hline Textil Caballero & 15 & 0,77 & 1,13 \\
\hline Textil Señora & 38 & 1,11 & 0,96 \\
\hline Textil & 8 & 0,31 & 0,89 \\
\hline Textil Otros & 64 & 1,00 & 0,35 \\
\hline Deportes & 14 & 1,13 & 0,65 \\
\hline Discos/CD/Vídeo & 41 & 0,74 & 0,69 \\
\hline Optico & 21 & 0,41 & 0,17 \\
\hline Librerías & 26 & 0,73 & 0,27 \\
\hline Bricolage/Hogar & 10 & 2,56 & 3,34 \\
\hline Tiendas 24 h. & 21 & 2,86 & $\mathbf{0 , 6 6}$ \\
\hline TOTAL & $\mathbf{5 6 4}$ & $\mathbf{1 , 1}$ & \\
\hline Fuente: Encuesta Nacional sobre Pérdida Desconocida & & \\
\hline
\end{tabular}

\section{Boletín Criminológico $N^{\circ} 56$ Noviembre-Diciembre 2001 Página 2}


TA B L A 2

Pérdida desconocida y gastos de seguridad por C C.A A.

\begin{tabular}{|c|c|c|c|}
\hline $\begin{array}{c}\text { FORMATOS } \\
\text { COMER CIALES }\end{array}$ & $\mathrm{N}^{\mathrm{a}}$ EMPRESAS & $\begin{array}{c}\text { PÉRDIDA DESC. } \\
\text { Media }(\%)\end{array}$ & $\begin{array}{c}\text { SEGURID A D } \\
\text { Media }(\%)\end{array}$ \\
\hline Andalucía & 94 & 0,86 & 0,46 \\
\hline Aragón & 25 & 1,26 & 1,36 \\
\hline Asturias & 19 & 0,67 & 1,81 \\
\hline B aleares & 12 & 1,35 & 0,64 \\
\hline Canarias & 18 & 1,90 & 0,39 \\
\hline Cantabria & 11 & 1,85 & 2,90 \\
\hline Castilla-La M ancha & 16 & 1,01 & 0,21 \\
\hline Castilla-León & 51 & 0,70 & 0,22 \\
\hline Cataluña & 123 & 1,16 & 0,55 \\
\hline Extremadura & 12 & 0,96 & 0,67 \\
\hline Galicia & 37 & 1,33 & 0,73 \\
\hline M adrid & 72 & 1,13 & 0,46 \\
\hline Murcia & 11 & 1,32 & 1,69 \\
\hline Navarra & 9 & 1,16 & 1,09 \\
\hline País Vasco & 49 & 1,51 & 1,14 \\
\hline Rioja & 4 & 1,18 & 0,48 \\
\hline Valencia & 59 & 1,04 & 0,43 \\
\hline TOT A L & 622 & 1,12 & 0,67 \\
\hline
\end{tabular}

edad del cliente o del empleado, concentrándose el mayor riesgo de cometer delito en los de menos de treinta años, descendiendo el riesgo conforme se incrementa la edad.

No hay un perfil claro de las personas que cometen las infracciones. Se estima que el $75 \%$ de las sustracciones se corresponden con acciones impulsivas, de lo que se deduce que el principal foco de atención de la organización comercial no ha de ser precisamente el infractor profesional sino, más bien, uno ocasional y emocional.

4. LA PREVENCIÓN DE LA PÉRDIDA DESCONOCIDA

Se calcula que el sector de la distribución en España tuvo en 1995 una pérdida desconocida valorada en 135.000 millones de pesetas. La importancia de la prevención de la pérdida desconocida la podemos contemplar con un sencillo ejemplo. Una empresa que sufre diariamente una sustracción de un producto cuyo precio es de 100 pesetas va a tener que afrontar una pérdida anual de 20.000 pesetas. Si el beneficio que se ob- tiene con el producto es del $2 \%$, deberá vender un millón adicional de pesetas en productos solamente para compensar esa pérdida, o bien, expresado en unidades de productos, tendrá que vender 10.000 unidades más.

\subsection{La inversión en seguridad}

Los gastos en sistemas de seguridad están relacionados directamente con el nivel de ventas, por lo que una mayor facturación provoca una mayor inversión en sistemas de protección.

Una tercera parte de las empresas comerciales que tienen una facturación inferior a los $500 \mathrm{mi}-$ llones de pesetas no han realizado ningún gasto en seguridad. Esa cifra se reduce hasta un $15 \%$ para aquellos negocios que venden entre 500 y 5.000 millones de pesetas. Para el 3\% de éstas, el gasto en seguridad está enmarcado predominantemente entre el 0 y el $0,2 \%$, siendo superior al $0,8 \%$ para las organizaciones con mayor facturación.

Las formas comerciales que sufren mayores pérdidas desconocidas son las tiendas de 24 horas
(2,86\% sobre ventas), los grandes almacenes $(2,79 \%)$ y los centros de bricolage/hogar $(2,56 \%)$. El lector puede comparar estas pérdidas con los recursos que se invierten por este concepto en la tabla $n^{\circ} 1$.

A partir de la información que proporciona la Encuesta Nacional sobre la pérdida desconocida, realizada por la Universidad de Barcelona en 1995, hemos relacionado la pérdida desconocida con los gastos de seguridad de distintas fórmulas comerciales. De dicha comparación destacamos, en primer lugar, que determinadas formas comerciales tienen bajas pérdidas desconocidas e invierten poco en seguridad, siendo los establecimientos más representativos las ópticas y las librerías.

En segundo término, existen formas comerciales con bajas pérdidas desconocidas y alta inversión en seguridad, destacando las tiendas dedicadas al textil, a la venta de discos y vídeos y los supermercados. Esto nos lleva a pensar que se produce un exceso de inversión en relación al volumen

\section{Boletín Criminológico $N^{0} 56$ Noviembre-Diciembre 2001 Página 3}


de siniestros. Sin embargo, no sabemos si las pérdidas reducidas son consecuencia de la seguridad elevada y, por lo tanto, desconocemos qué podría ocurrir si los gastos en seguridad disminuyeran.

Además, hay unos tipos de establecimientos comerciales que tienen unas pérdidas desconocidas y unos gastos en seguridad elevados, como son las tiendas de 24 horas, los grandes almacenes y los hipermercados. Son formas comerciales en las que se da una mayor correlación entre la inversión en seguridad y el hurto.

Y, por último, se distinguen las organizaciones con altas pérdidas desconocidas y bajos niveles de inversión en seguridad, como son las tiendas de deportes y de bricolage. No parece razonable en tales casos una tan escasa atención a la seguridad dado el elevado número de incidencias, por lo que sería aconsejable incrementar la inversión si se desea disminuir la pérdida.

Un análisis geográfico de la situación nos permite describir cuatro posiciones distintas:

La primera situación está representada por las comunidades de Andalucía, Valencia, CastillaLeón y Castilla-La Mancha, que reflejan unos niveles bajos tanto de pérdidas desconocidas como de inversión en seguridad (véase tabla 2)

El segundo escenario está caracterizado por un bajo índice de hurtos y una elevada inversión en seguridad. En Asturias se ha producido un descenso importante en el volumen de incidencias,por lo que pensamos que la inversión en seguridad ha tenido una repercución destacable.

Cantabria, Murcia, Pais Vasco, Aragón y Navarra constituyen las comunidades con niveles de hurto y de inversión en seguridad elevados. Los gastos de seguridad se convierten en una inversión imprescindible.

$\mathrm{Y}$ el resto de comunidades autónomas está caracterizado por altas pérdidas por hurto y baja inversión en seguridad, por lo que nos atrevemos a aconsejar la necesidad de incrementar los gastos en la prevención de delitos, como punto de partida para conseguir una reducción del volumen de incidencias.

\subsection{Medidas de control inter-} no y de seguridad

En la tabla $n^{\circ} 3$ se presentan las medidas de seguridad que habitualmente utilizan los comercios para prevenir el hurto externo.

Con respecto a las medidas de control que pueden adaptarse a nivel interno destacan las siguientes:

1.Controles a través de sistemas informáticos para conocer las reducciones de stocks en la recepción, almacén, zonas de despacho de las mercancías, y en el propio establecimiento de venta. Estos controles consisten en registros de las roturas, pérdidas y consumo interno, así como en el control regular de errores en el marcaje de precios y la codificación. Asimismo, se pueden establecer controles administrativos que ayuden a eliminar las diferencias de stocks, especialmente controles en la gestión de caja. Entre estos se pueden citar la utilización de cupones y notas de crédito, límites autorizados en las cancelaciones de ventas, protección con clave de acceso y procedimientos claros para las devoluciones y cambios. 2. Otra medida es el control de gestión, que analiza los puntos críticos del sistema con el fin de determinar las áreas más débiles, como las cajas de salida. A tal efecto se puede prever que un personal experto realice compras programadas de forma anónima para verificar que el personal de las líneas de cajas actúan correctamente en el registro de las mismas.

3.Se puede trabajar la motivación del personal, ya sea a través de la formación ya sea con determinadas formas de recompensa. Todo ello facilita el compromiso de los empleados, favoreciendo la minoración de las pérdidas, pero sobre todo el incremento de la productividad en el trabajo. Tampoco hay que descuidar la selección del personal, así como su seguimiento mediante pruebas de actitud e indicadores basados en el comportamiento del empleado.

Tabla $n^{\circ}$ 3. Medidas de Control Interno y Seguridad

\begin{tabular}{|l|c|}
\hline Escáner con terminal en punto de venta & $61,13 \%$ \\
\hline Lectores portátiles con códigos de barras & $47,92 \%$ \\
\hline Lectores de códigos de barras en recepción de la mercancía & $11,98 \%$ \\
\hline Sistemas de protección electrónica EAS & $59,29 \%$ \\
\hline Sistemas de circuitos cerrados de televisión & $38,40 \%$ \\
\hline Elementos pasivos: cables y antenas & $27,19 \%$ \\
\hline Vitrinas & $52,87 \%$ \\
\hline Personal de vigilancia con uniforme & $19,70 \%$ \\
\hline Personal de vigilancia sin uniforme o detectives & $6,75 \%$ \\
\hline
\end{tabular}

\section{Boletín Criminológico $N^{o} 56$ Noviembre-Diciembre 2001 Página}

